\title{
Fiber Investment and Access under Uncertainty: Long-Term Contracts, Risk Premia, and Access Options
}

\author{
Marc Bourreau • Carlo Cambini · Steffen \\ Hoernig • Ingo Vogelsang
}

Received: date / Accepted: date

\begin{abstract}
Regulated access schemes shape incentives for both investment and entry in next-generation networks. We study in a general duopoly setting whether and how risk premia, access options or long-term contracts improve those incentives as compared to standard access pricing. The first two do so: Risk premia guarantee highest coverage, while distorting retail pricing. Access options safeguard undistorted retail competition, but are not effective in the most costly areas. On the other hand, long-term contracts have little scope to increase coverage because they intensify retail competition.
\end{abstract}

JEL: L51, L96

Keywords Next generation networks · Uncertainty · Risk Premium · Access Options · Long-Term Contracts

Marc Bourreau acknowledges financial support from the Orange/Telecom Paris partnership. Carlo Cambini has been partially supported by "Ministero dell'Istruzione, dell'Universitá e della Ricerca" award "TESUN- 83486178370409 finanziamento dipartimenti di eccellenza CAP. 1694 TIT. 232 ART. 6".

Steffen Hoernig was funded by Fundação para a Ciência e a Tecnologia (UID/ECO/00124/2013, UID/ECO/00124/2019 and Social Sciences DataLab, LISBOA-010145-FEDER-022209), POR Lisboa (LISBOA-01-0145-FEDER-007722, LISBOA-01-0145FEDER-022209) and POR Norte (LISBOA-01-0145-FEDER-022209).

Marc Bourreau, ORCID 0000-0003-3913-3014

Telecom Paris, Institut Polytechnique de Paris

Carlo Cambini, ORCID 0000-0002-7471-8133

Politecnico di Torino

Steffen Hoernig (corresponding author), ORCID 0000-0003-1461-0048

Nova School of Business and Economics, Rua da Holanda 1, 2775-405 Carcavelos, Portugal Tel.: +351-21 3800000

E-mail: shoernig@novasbe.pt

Ingo Vogelsang, ORCID 0000-0002-2020-1569

Boston University 


\section{Introduction}

In many countries, including those of the European Union, owners of fixed telecommunications networks are obliged to give access to alternative operators providing competing retail services such as voice communications, broadband access and even subscription television. The pricing of this access is a thorny issue, and several different approaches have been used over time. The standard regulatory mechanism adopted by both the EU and other regulators worldwide is the "cost orientation" principle, according to which the access charge should fully cover access costs. Cost orientation can be seen as a natural obligation in cases involving access to an essential facility held by an incumbent operator, but its implementation might differ considerably. The most prominent method is the LRIC (long-run incremental cost) approach to define access charges. Since the mid-1990s it has been used widely by regulators, especially in the EU. This method has been very successful in generating low prices and creating service competition that allowed for some product differentiation. It worked well for legacy networks that required no or little new investment: Incumbents earned good returns and were shielded from expropriation tendencies of regulators, while maintaining retail market competition.

Still, early on LRIC access charges were criticized as hindering investments in new, to-be-sunk networks, in particular in the presence of uncertainty about future demand and willingness to pay. The strongest advocate of this critique was Hausman (1997) based on the work of (his MIT colleague) Pindyck and others, who developed "real option" theory (see Dixit and Pindyck 1994, Pindyck 2007). Empirical evidence by many authors, surveyed first by Cambini and Jiang (2009); later by Briglauer et al. (2015), confirms Hausman's conjecture. While these criticisms of the LRIC approach arose already when legacy copper networks were opened to access, they have gained a new urgency due to the perceived necessity of investment in dense fiber networks, in fiberto-the-home and in increased capacity to serve the infrastructure for mobile broadband. Incentives for network coverage, while maintaining a suitable level of competition and entry, are now at the forefront of regulatory policy concerns as broadband markets face a rather slow transition from traditional copper to high-capacity fiber networks, even though these investments are considered essential for economic growth. ${ }^{1}$ Indeed, the new EU regulatory framework for telecommunications of 2018 (EECC) explicitly introduces investment in ultrafast coverage as an additional main policy goal besides enhanced competition, in order to achieve the European broadband coverage goals for 2020 and 2025 (European Commission 2010 and 2016, respectively).

As a result, regulators need to adapt existing network access schemes to simultaneously guarantee competition and network roll-out, in particular when future demand for high-capacity services is still quite uncertain. Hausman (1997, 1999) suggested additional mark-ups on LRIC prices (also called "risk

\footnotetext{
1 See Abrardi and Cambini (2019) for a survey about the impact of ultra-fast broadband investment on different economic dimensions.
} 
premia") as a remedy for the investment problem. We consider this proposal, as well as ex ante option payments for the right to buy access at LRIC without mark-up, and long-term contracts. Our goal is to contribute to the current policy debate about how to achieve sufficient network coverage in Europe, where LRIC access charges have been used in almost all countries and also where risk premia are being evaluated in order to provide incentives for investment in ultra-fast broadband networks. Therefore, in order to capture both goals of coverage and competition for the benefit of consumers, we concentrate on total coverage and entry thresholds as performance measures, while also keeping track of the effect of access schemes on consumer and total surplus.

Model and Results: We analyze a model that focuses on geographic coverage of a next generation network, i. e., ultra-fast broadband based on fiber-optic technology. The incumbent firm chooses which areas to cover before knowing the level of demand. The latter becomes publicly known when the investment has been undertaken. Since entrants ask for access after demand is observed, they can cherry-pick the markets to enter, which in turn affects investment incentives. Different regions will need different types of access schemes, and thus we consider separately how well these schemes fare for each specific area that lacks coverage under standard access regulation.

Standard access schemes make entrants pay by usage and let them choose when and where to enter. As pointed out by Hausman (1997) and others, this affords the entrants a free "access option", i.e. the choice to only ask for access when demand turns out to be high. The option value arises by protecting the entrant against potential downsides, as discussed in the real-options literature. But what really matters for our purpose is the "option externality" imposed on the incumbent by the exercise of the entrant's option, which consists in the curtailing of the incumbent's returns if demand is high. It is this option externality that reduces the incumbent's incentives for investment, and what we are investigating are different schemes to compensate the incumbent.

The maximum coverage that can possibly be achieved, at least without government subsidies, is the coverage chosen by a monopolist: Entry and competition dissipate profits, and therefore, irrespectively of how investment costs are shared, total profits under competition cannot cover the investment cost for the most outlying areas. Therefore we take monopoly coverage as the benchmark. Second, the observed levels of demand for which the entrant asks for access in different areas depend on the access scheme. We characterize the minimum level of demand for which entry happens under the different access schemes.

Our results are as follows: As a first extension to standard access charges we consider the imposition of an additional margin just set high enough to make the incumbent invest in uncovered areas. This can be understood as a risk premium that compensates the incumbent partially for the risk it is subjected to ex post by the uncertain entry decision. We find that this margin can be set at a level that both makes the incumbent invest and safeguards some (though less) entry. This margin increases with the level of investment 
cost, which raises retail prices and leads to lower consumer surplus compared to the case where area could have been covered without a risk premium.

We then consider access options, which involve an up-front payment from the entrant to the incumbent plus access at standard rates ex post. We determine the minimum up-front payment that just makes the incumbent invest, and find that coverage can increase substantially as compared to standard access, while ex post market outcomes are not distorted. Still, due to profit dissipation full monopoly coverage cannot be achieved while maintaining entry.

Finally, we look at long-term contracts, where the entrant commits ex ante to buying a certain wholesale quantity. While this type of contract reduces uncertainty for the investing firm, it has the drawback that ex post competition will be fiercer, reducing returns on investment and potentially even lowering coverage instead of increasing it.

A key point of our analysis is that different types of access schemes need to be used in different types of areas. If the aim of the regulator is to guarantee coverage with a minimum distortion of the local retail market equilibrium, access options should be the first choice. Yet, these are not feasible in the most expensive and outlying areas. In the latter, it is necessary to increase the incumbent's returns by adding a risk premium over the access charge. Any accompanying reduction in achievable surplus due to the risk premium will be limited to this specific area.

Related Literature: The literature on access regulation is quite extensive (Vogelsang 2003), but it is scant when it comes to setting access charges in the presence of demand uncertainty.

Authors in some early papers analyze the investment incentives in the presence of demand uncertainty with different forms of regulation and market competition. Guthrie et al. (2006) compare backward-looking (historical cost) vs forward-looking (current cost) access pricing rules under cost uncertainty with a decreasing trend. Similar to us they conclude that setting access prices ex post retards investment. Hori and Mizuno (2006) analyze the effect of access charges on firms' (both incumbent and entrant) incentives to invest in a network facility with a stochastically growing demand. They show that in the presence of an increasing access charge, the incumbent may have the incentive to preempt the market and therefore invest first in areas where an entrant may find it profitable to invest, too. In a companion paper (Hori and Mizuno, 2009), the authors compare the impact of facility based competition and service based competition on the incentive to invest in a new advanced network. They show that, when the monopoly rent due to uncertainty is large, the initial introduction of the new infrastructure is made earlier under facilitybased competition than under service-based competition, while the opposite emerges when the degree of uncertainty and thus the monopoly rent is relative small. Note that these papers all assume that uncertainty never actually resolves, implying that the firms face the same uncertain future at every instant. This approach is different from ours since we assume that demand uncertainty 
resolves and access seekers might thus have an incentive to wait to reduce demand risk.

Klumpp and $\mathrm{Su}$ (2010) are the first to consider a LRIC access pricing rule and its effect on (quality) investment. Under certainty, they show that the level of investment increases with the number of access seekers. Klumpp and $\mathrm{Su}$ (2015) acknowledge that this result is not robust and empirically show that in US electricity markets the opposite holds. They also consider forwardlooking LRIC under demand uncertainty and conclude that access truncates returns in the good state, while in the bad state the incumbent is a monopolist if the investment cost is high. Contrary to the case of certainty, investment is lower than under monopoly if there are many entrants.

Nitsche and Wiethaus (2011) compare different access pricing schemes. In particular, they compare LRIC access regulation and a risk sharing agreement - where the incumbent and the entrant operators decide to invest jointly (i.e. to co-invest) rather than individually. They show that risk sharing can lead to both stronger investment incentives and higher consumer welfare than standard LRIC access regulation. Their framework differs from ours in several important respects: First, they assume that investment increases quality, while we model and determine equilibrium coverage explicitly. Second, they assume guaranteed access to the copper network as the entrant's outside option and only two demand states, while we consider a continuum of states and are therefore able to determine entry thresholds. Third, their ex post LRIC charge is determined retroactively as a function of realized (rather than expected equilibrium) quantities, which changes the strategic interaction and puts both incumbent and entrant in a symmetric position. We follow regulatory practice and assume that firms take the access charge as given when they choose their retail strategies, subjecting the entrant to a higher perceived marginal cost than the incumbent.

Inderst and Peitz (2014) provide a high-level discussion of many (mostly unregulated) access schemes, listing their advantages and disadvantages. They consider mostly fixed fees including options, but also touch on usage-based prices and conclude that while the latter reduce competitive intensity (if above marginal cost) they increase incentives for investment as compared to fixed fees. ${ }^{2}$ While they carefully model firms' decisions both to invest in quality and to enter, they do not consider coverage as such, which is the important policy issue at the center of the present paper. Moreover, we provide a direct comparison of access schemes in the pursuit of this coverage goal.

Using a similar coverage game, Bourreau et al. (2018) analyze co-investment schemes and show that the presence of uncertainty reduces total coverage. A recent companion paper, Bourreau et al. (2019), focuses on how to make entrants co-invest early rather than wait (e.g., in France first investors are required to allow later co-investment of other companies), using some related policy measures. These papers deal with the impact of co-investment arrange-

2 Clark and Easaw (2007) use an option pricing approach to define access charges assuming fixed retail prices. Competitive effects are therefore absent in their model. 
ments on the incentives to invest in ultra-fast broadband networks but they do not consider explicitly the role of access regulation.

Briglauer et al. (2015) and Abrardi and Cambini (2019) review the empirical literature and conclude that, while policy conclusions tend to be ambiguous, there is a strong indication that access obligations negatively affect investment incentives. In a recent empirical paper, Briglauer et al. (2018) study how access regulation of legacy and fiber networks affects the incentives to invest in ultra-fast broadband networks. They show that fiber access obligations lead to a large reduction of the incumbents' investments.

\section{Model Setup}

We consider a setting where an incumbent firm rolls out a next generation network over a set of areas indexed by $z \geq 0$. These areas are equal in their demand characteristics, but have an increasing cost of coverage $c(z)$, where $c($.$) is continuous, increasing and c(0)=0$ (This setup can alternatively be interpreted as depicting increasingly dispersed customers with a constant cost of being covered). Investment cannot be replicated, therefore an entrant firm must ask for access. ${ }^{3}$ Consumers' willingness to pay is uncertain and is revealed after the investment is made, therefore, dependent on the access scheme, the entrant may be able to wait for this information before asking for access. ${ }^{4}$ Regulation, investment and entry occur in each area separately, and the ultimate aim is to determine the extent of coverage and the accompanying local market outcomes.

Thus the timing of our model is as follows: i) Taking into account local investment costs, the regulator defines access schemes tailored to specific areas; ii) if locally available, the entrant may enter into a long-term contract or buy an access option; iii) the incumbent decides in which areas to invest, after which demand is realized; iv) both operators observe local willingness to pay, under the prevailing access scheme the entrant decides whether to enter or not, and profits are realized.

In order to make our results both intuitive and robust, we impose assumptions directly on the outcomes of local market competition, instead of deriving them from some specific model. Our model encapsulates all more specific models of price or quantity competition, product differentiation or homogeneous goods, or even bundle competition, which satisfy these assumptions. Willingness to pay $\delta$ in any given area $z$ is distributed on $[\underline{\delta}, \bar{\delta}], \bar{\delta} \leq \infty$, with an (atomless) distribution function $F$. Profits are continuous in $\delta$ and almost everywhere differentiable in the access charge $a$ set by the regulator.

\footnotetext{
3 Any investment by entrants would occur in areas already covered by the incumbent, such as cities. Since we want to focus on coverage of marginal areas, we abstract from entrant investment. Moreover, we assume that next generation retail services are so superior to copper-based services that previous copper coverage and access provisions do not matter.

4 Willingness to pay in different areas may be correlated, but this will not be relevant for what follows.
} 
Ex post profits for the entrant are $\Pi_{e}^{*}(a, \delta)$, increasing in $\delta$. Entry occurs only in the good demand states, i.e. if and only if willingness to pay $\delta$ is high enough as compared to $a$. More formally, there is a strictly increasing and differentiable function $\hat{\delta}(a)$ such that $\Pi_{e}^{*}(a, \delta) \gtreqless 0$ for $\delta \gtreqless \hat{\delta}(a)$, and an access charge $\bar{a}$ such that $\hat{\delta}(\bar{a})=\bar{\delta}$ (entry is foreclosed if $a>\bar{a}$ ).

The incumbent obtains ex post profits of $\Pi_{0}^{*}(a, \delta)$, which are equal to monopoly profits $\Pi_{m}^{*}(\delta)<\infty$ if no entry occurs. If the entrant is active, i.e. $\delta \geq \hat{\delta}(a), \Pi_{0}^{*}$ and joint profits $\Pi_{0}^{*}+\Pi_{e}^{*}$ are strictly increasing in $a$, with $\Pi_{0}^{*}<\Pi_{0}^{*}+\Pi_{e}^{*}<\Pi_{m}^{*}$ (competition dissipates profits). We may have $\Pi_{0}^{*}(a, \hat{\delta}(a))<\Pi_{m}^{*}(\hat{\delta}(a))$, for instance if the entrant has fixed costs; in this case the incumbent's profits are discontinuous at this point.

A final assumption is needed for assessing the welfare impact of different outcomes: Since a higher access charge raises retail prices, consumer surplus $C S(a, \delta)$ and total surplus $\Pi_{0}^{*}+\Pi_{e}^{*}+C S$ are strictly decreasing in $a .^{5}$

In an Online Appendix we report on a simple model which gives rise to local market equilibria with the above-mentioned properties, involving quantity competition under inverse demand $P=\delta(2-Q)$ with $\delta$ uniformly distributed on $[1-\sigma, 1+\sigma]$ and $0<\sigma<1$ indicating the degree of uncertainty. There we also provide an illustrative numerical simulation of our more general results.

For the standard tariff with a simple access charge $a$ per unit, ex post entry occurs for $\delta \geq \hat{\delta}(a)$, with ex ante expected profits

$$
\begin{aligned}
E\left[\Pi_{0}^{*}(a, \delta)\right] & =\int_{\underline{\delta}}^{\hat{\delta}(a)} \Pi_{m}^{*}(\delta) d F(\delta)+\int_{\hat{\delta}(a)}^{\bar{\delta}} \Pi_{0}^{*}(a, \delta) d F(\delta) \\
& =E\left[\Pi_{m}^{*}(\delta)\right]-\int_{\hat{\delta}(a)}^{\bar{\delta}}\left[\Pi_{m}^{*}(\delta)-\Pi_{0}^{*}(a, \delta)\right] d F(\delta), \\
E\left[\Pi_{e}^{*}(a, \delta)\right] & =\int_{\hat{\delta}(a)}^{\bar{\delta}} \Pi_{e}^{*}(a, \delta) d F(\delta) .
\end{aligned}
$$

Finally, the incumbent covers exactly the areas for which expected profits cover investment costs. If no entry occurs, maximum coverage $z^{m}$ (the monopoly benchmark) is given by $c\left(z^{m}\right)=E\left[\Pi_{m}(\delta)\right]$. With entry, due to profit dissipation, coverage is reduced to $z^{s}$ with

$$
c\left(z^{s}\right)=E\left[\Pi_{0}^{*}(a, \delta)\right]<E\left[\Pi_{m}(\delta)\right]
$$

We will now determine the potential of alternative access schemes to increase coverage while maintaining entry. In doing so, we evaluate both coverage and consumer surplus.

\footnotetext{
5 It would be natural to assume that the incumbent's profits and consumer surplus are increasing in $\delta$, but this assumption is not needed.
} 
Table 1 WACC and next generation risk premia in the EU.

\begin{tabular}{lll}
\hline Country & Standard WACC & Risk Premium \\
\hline Denmark & $6.78 \%$ & $2 \%$ \\
Finland & $6.50 \%$ & $1.1 \%$ \\
Italy & $8.77 \%$ & FTTC 1.2, FTTH $3.2 \%$ \\
Luxembourg & $7.10 \%$ & $0.61 \%$ \\
Netherlands & $6.06 \%$ & $2.6 \%$ \\
United Kingdom & $7.90 \%$ & $1 \%$
\end{tabular}

WACC: weighted average cost of capital; FTTC: fibre to the curb; FTTH: fibre to the home. Source: Cullen International.

\section{Risk Premia}

The first alternative scheme we consider is adding a risk premium, which compensates the incumbent for bearing both demand uncertainty and the exercise of the entry option. This is current practice in a number of member states of the EU, where an additional margin is applied to the weighted average cost of capital (WACC) that enters the computation of the access charge, see Table $1 .^{6}$

Increasing WACC indirectly results in a higher access charge. For simplicity, we look at increasing the access charge directly, as we want to focus on the effect of adding a margin. For $a<\bar{a}$, the effects of the access charge on the incumbent's expected profits are

$\frac{d}{d a} E\left[\Pi_{0}^{*}(a, \delta)\right]=\int_{\hat{\delta}(a)}^{\bar{\delta}} \frac{\partial \Pi_{0}^{*}(a, \delta)}{\partial a} d F(\delta)+\frac{d \hat{\delta}(a)}{d a}\left[\Pi_{m}^{*}(\hat{\delta}(a))-\Pi_{0}^{*}(a, \hat{\delta}(a))\right] f(\hat{\delta}(a))$,

i.e., they do increase with the access charge. ${ }^{7}$

We first observe that if the aim of the risk premium is to increase coverage (rather than generically to compensate the incumbent for risk), there is no need to impose a risk premium for $z \leq z^{s}$ because these areas are covered anyway, while doing so would reduce consumer surplus and welfare. Second, an access charge $a \geq \bar{a}$ simply keeps the entrant out and thus leads to monopoly coverage. The latter of course neglects the loss in consumer surplus. Thus we consider, for each area $z \in\left(z^{s}, z^{m}\right]$, the lowest local margin $m$ that still lets the incumbent break even in expectation:

$$
c(z)=E\left[\Pi_{0}^{*}(a+m, \delta)\right]
$$

This margin $m$ increases with $z$, from $m=0$ at $z^{s}$ to $m=\bar{a}-a$ at $z^{m}$. In the newly covered areas, this added margin has two negative effects: It directly reduces consumer surplus after entry, and it reduces the set of demand states in which entry happens in the first place. Thus there is a cost in terms of

\footnotetext{
6 This augmented WACC is then applied to the fixed capital employed to obtain a capital cost estimate, after which an estimate of operating costs is added.

7 We have made a weaker assumption on the entrant; but e.g. with quantity competition and strategic substitutes its profits are indeed decreasing in the access charge.
} 
lost potential consumer surplus and welfare when risk premia are used. On the other hand, the above also shows that coverage of all areas up to the monopoly benchmark can be achieved while at least some entry continues to be viable.

\section{Access Options}

The logic of access options is quite different from mark-ups on the standard access charges. It is to formalize the notion that the right to access after the network has been built is of value to the entrant and it puts a price on it. This price is paid ex ante and increases the incumbent's incentives to build the network in the first place. Once the option has been bought, the entrant's choice of entry and the resulting retail market outcomes are the same as under the standard tariff with the same access charge.

Again, there is no need (on the incentive side) to intervene in the covered areas $z \leq z^{s}$. For each uncovered area $z \in\left(z^{s}, z^{m}\right]$, the entrant must pay an access option price $A$ that gives it the right to ask for access later at an access charge $\tilde{a}$. In order to provide incentives to invest, the option price must cover at least the expected loss of the incumbent, $E\left[\Pi_{0}^{*}(\tilde{a}, \delta)\right]-c(z)+A \geq 0$, while acceptance by the entrant implies that it cannot exceed the entrant's expected profits, $A \leq E\left[\Pi_{e}^{*}(\tilde{a}, \delta)\right] .{ }^{8}$ Combining both constraints, we find

$$
c(z) \leq c\left(z^{o}\right)=E\left[\Pi_{0}^{*}(\tilde{a}, \delta)+\Pi_{e}^{*}(\tilde{a}, \delta)\right] .
$$

This means that the maximum coverage $z^{o}$ that can be reached by using access options is limited by the joint profits of both firms at the access charge $\tilde{a}$. Since these joint profits are below the monopoly profit, this implies that coverage with entry remains below the monopoly benchmark level. In more expensive areas, access options will lead to monopoly.

As with risk premia, the regulator faces a trade-off between coverage and consumer surplus in the newly covered areas. ${ }^{9}$ But since expected joint profits exceed the incumbent's profit, at any given access charge more areas can be covered, or equivalently, coverage of any specific area can be achieved at a lower access charge than with a risk premium,

$$
E\left[\Pi_{0}^{*}(\tilde{a}, \delta)+\Pi_{e}^{*}(\tilde{a}, \delta)\right]=E\left[\Pi_{0}^{*}(a+m, \delta)\right]
$$

with $\tilde{a}<a+m<\bar{a}$. This leads both directly to higher consumer surplus and welfare, and to more ex post entry. Still, the same coverage can be reached by

\footnotetext{
8 We assume here that access without option payment is no longer offered. If it was still available, then one would set a lower access charge in return for the option payment, $\tilde{a}<a$, and the constraint on the option price would be stricter, $A \leq E\left[\Pi_{e}^{*}(\tilde{a}, \delta)-\Pi_{e}^{*}(a, \delta)\right]$. As a result, achievable coverage is lower.

9 As pointed out by Inderst and Peitz (2014), combining an access option with a lower access charge, while increasing consumer surplus, further reduces investment incentives since the retail market becomes more competitive.
} 
setting the access $\tilde{a}$ high enough (up to $\bar{a}$ in the limit). In other words, the access option is welfare-superior to a risk premium. ${ }^{10}$

\section{Long-Term Contracts}

As a final alternative we consider access contracts where the entrant commits ex ante to buying a given quantity $\bar{q}_{e}$ at an access charge $a_{0}$, with the possibility to buy more access later at price $a$. The idea behind these contracts is to eliminate the access externality, and reduce uncertainty for the investor, by guaranteeing a minimum wholesale revenue in all demand states. We will show now that these contracts have strong adverse side effects because they make the market more competitive ex post, for two reasons. First, since the entrant has committed to paying for the quantity $\bar{q}_{e}$, ex post the cost $a_{0} \bar{q}_{e}$ is sunk and therefore the entrant's effective marginal cost, up to $q_{e}=\bar{q}_{e}$, is zero, which makes the entrant compete more fiercely. Second, for the same reason it enters in more states of demand.

In order to formalize this, denote by $q_{e}^{*}(a, \delta)$ the ex post Nash equilibrium (in the absence of the contract) quantity at access charge $a$ and willingness to pay $\delta$; assume that $q_{e}^{*}$ is strictly increasing in $\delta$ and strictly decreasing in $a$. We now need to distinguish three cases.

Case 1: The committed quantity is too small ex post, i.e. $\bar{q}_{e}<q_{e}^{*}(a, \delta)$, or in other words the state of demand is too good: $\delta>\tilde{\delta}\left(a, \bar{q}_{e}\right)$ for some function $\tilde{\delta}$ increasing in $a$ and $\bar{q}_{e}$. The entrant buys the additional quantity $q_{e}^{*}(a, \delta)-\bar{q}_{e}$, and profits are $\Pi_{0}^{*}(a, \delta)+\left(a_{0}-a\right) \bar{q}_{e}$ and $\Pi_{e}^{*}(a, \delta)-\left(a_{0}-a\right) \bar{q}_{e}$.

Case 2: The entrant sells exactly $\bar{q}_{e}$ in equilibrium, i.e. $q_{e}^{*}(a, \delta) \leq \bar{q}_{e} \leq$ $q_{e}^{*}(0, \delta)$, or $\tilde{\delta}\left(0, \bar{q}_{e}\right) \leq \delta \leq \tilde{\delta}\left(a, \bar{q}_{e}\right)$. This market outcome corresponds to the Nash equilibrium at a virtual marginal cost $\alpha\left(\bar{q}_{e}, \delta\right)$, decreasing in $\bar{q}_{e}$, defined by $\bar{q}_{e}=q_{e}^{*}(\alpha, \delta)$, with $\alpha\left(\bar{q}_{e}, \delta\right)=a$ at $\bar{q}_{e}=q_{e}^{*}(a, \delta)$ and $\alpha\left(\bar{q}_{e}, \delta\right)=0$ at $\bar{q}_{e}=q_{e}^{*}(0, \delta)$. The resulting profits are $\Pi_{0}^{*}\left(\alpha\left(\bar{q}_{e}, \delta\right), \delta\right)+\left(a_{0}-\alpha\left(\bar{q}_{e}, \delta\right)\right) \bar{q}_{e}$ and $\Pi_{e}^{*}\left(\alpha\left(\bar{q}_{e}, \delta\right), \delta\right)-\left(a_{0}-\alpha\left(\bar{q}_{e}, \delta\right)\right) \bar{q}_{e}$.

Case 3: $\bar{q}_{e}$ is too large, $\bar{q}_{e}>q_{e}^{*}(0, \delta)$ or $\delta<\tilde{\delta}\left(0, \bar{q}_{e}\right)$. The optimal choice for the entrant is to use only the quantity $q_{e}^{*}(0, \delta)$, with profits of $\Pi_{0}^{*}(0, \delta)+a_{0} \bar{q}_{e}$ and $\Pi_{e}^{*}(0, \delta)-a_{0} \bar{q}_{e}$.

\footnotetext{
10 While in the present setting the entrant will be worse off since the option price extracts part or all of his expected profits, access options continue to be welfare-superior when the entrant cannot be made worse off, e.g. if the standard access tariff $a$ were still available. But coverage cannot be increased, as $E\left[\left(\Pi_{0}^{*}+\Pi_{e}^{*}\right)(\tilde{a}, \delta)-\Pi_{e}^{*}(a, \delta)\right]<E\left[\Pi_{0}^{*}(a, \delta)\right]$ for $\tilde{a}<a$.
} 
The incumbent's ex ante expected profits, assuming that the entrant now always enters, ${ }^{11}$ are

$$
\begin{aligned}
E\left[\Pi_{0}\right] & =\int_{\underline{\delta}}^{\tilde{\delta}\left(0, \bar{q}_{e}\right)}\left[\Pi_{0}^{*}(0, \delta)+a_{0} \bar{q}_{e}\right] d F(\delta) \\
& +\int_{\tilde{\delta}\left(0, \bar{q}_{e}\right)}^{\bar{\delta}\left(a, \bar{q}_{e}\right)}\left[\Pi_{0}^{*}\left(\alpha\left(\bar{q}_{e}, \delta\right), \delta\right)+\left(a_{0}-\alpha\left(\bar{q}_{e}, \delta\right)\right) \bar{q}_{e}\right] d F(\delta) \\
& +\int_{\tilde{\delta}\left(a, \bar{q}_{e}\right)}^{\bar{\delta}}\left[\Pi_{0}^{*}(a, \delta)+\left(a_{0}-a\right) \bar{q}_{e}\right] d F(\delta) .
\end{aligned}
$$

It is clear that expected profits increase in $a_{0} \bar{q}_{e}$, but there are countervailing effects. The first term indicates that there is now competition in (some or all) previous monopoly states, at zero effective marginal cost. The second term shows that for medium demand states competition now occurs at the lower virtual marginal cost $\alpha\left(\bar{q}_{e}, \delta\right)<a$, while the third term is affected by the difference between $a_{0}$ and $a$. The overall effect on the incumbent's profits, as compared to the benchmark case, is ambiguous. ${ }^{12}$

\section{Conclusions}

Policy makers and regulatory institutions face a difficult trade-off between creating incentives for investment in next-generation fiber networks and maintaining competition via access provision. In this paper we compared several variants of pricing access and their effects on entry and coverage.

We first confirmed that, due to the diffusion of rents caused by entry, coverage under a standard access scheme is lower than for a monopolist, who provides maximum coverage without further subsidies. Existing European legislation only allows subsidies to be given in regions that will not be covered under market conditions. Our work complements this legal requirement by showing how market-led coverage can be increased, and by how much, if conditions for access obligations are rethought. This in turn helps policy makers to concentrate subsidies on the most outlying areas.

There is indeed scope for improving investment incentives. As reported in Table 2, we showed that risk premia, i.e. additional margins on top of the costbased access charge, can restore coverage incentives even in the most costly areas. This comes at the price, though, of increasing the entrant's marginal cost, reducing ex post entry and consumer surplus in the newly covered areas.

Access options, where the entrant pays an ex ante fee to gain access at standard access charges later on, do not affect ex post entry thresholds and

\footnotetext{
11 This would be the case without fixed costs. In their presence there would still be a monopoly in the very worst demand states.

12 In the simulation in the Online Appendix, a small committed quantity raises coverage by a little if uncertainty is high, and not at all if it is low. Higher committed quantities lower coverage significantly, though.
} 
Table 2 Outcomes under access schemes in previously uncovered areas

\begin{tabular}{|c|c|c|}
\hline & Coverage & $\begin{array}{c}\text { Per-area welfare } \\
\text { compared to standard } \\
\text { access charge }\end{array}$ \\
\hline $\begin{array}{c}\text { Risk } \\
\text { premia }\end{array}$ & $\begin{array}{l}\text { Up to monopoly level, with } \\
\text { an increasing risk premium }\end{array}$ & $\begin{array}{l}\text { Lower, decreasing } \\
\text { in risk premium }\end{array}$ \\
\hline $\begin{array}{l}\text { Access } \\
\text { options }\end{array}$ & $\begin{array}{l}\text { Accepted option, below } \\
\text { monopoly level; monopoly } \\
\text { in most costly areas }\end{array}$ & $\begin{array}{l}\text { Equal in option areas, } \\
\text { lower in monopoly }\end{array}$ \\
\hline $\begin{array}{l}\text { Long-term } \\
\text { contracts }\end{array}$ & $\begin{array}{c}\text { Ambiguous as compared to } \\
\text { standard access charge }\end{array}$ & $\begin{array}{c}\text { Higher in covered areas, } \\
\text { zero otherwise }\end{array}$ \\
\hline
\end{tabular}

do not distort ex post market outcomes. The incumbent's coverage increases strongly, though, but not all the way to monopoly coverage.

Long-term contracts where the entrant commits to buying some fixed minimum quantity after investment, on the other hand, do not tend to induce higher coverage, because any benefit from more certain wholesale demand is countered by more competitive retail markets ex post, reducing investment incentives.

Thus different access schemes are optimal depending on the type of area to be covered: Access options are preferable to risk premia where they are feasible, i.e. where the sum of profits without an extra access margin exceeds investment cost, because they do not distort ex post market outcomes. More outlying areas can only be covered using risk premia, which carry a cost in terms of achievable total surplus. To make this more intuitive, consider various types of countries that differ in their geography. In relatively flat countries, such as Belgium and the Netherlands, our results show that access options are the preferable solution to coverage issues. On the other hand, in countries where deployment costs increase steeply outside of urban areas (mountainous countries such as Italy and Switzerland), access options are not feasible (investment costs cannot be covered without adding an extra margin to the access price) and risk premia need to be used instead. In other countries that have both types of areas, such as France and Spain, the adoption of a mix of instruments is called for.

There are several issues that we leave for further research. First, we assumed throughout that the entrant has only one alternative to choose from, since we compared all schemes to the outside option of staying out of the local market. It is easy to see that the entrant would prefer the standard access scheme to each of the three alternatives, because these involve either additional payments or restrictions on ex post choices. We did not consider (and this may not be a very interesting question anyway) how the entrant would freely choose among the alternative schemes.

Second, by concentrating on a setting with a single entrant, we have not fully modeled the potential benefits from competition, nor the implications of more entrants on using the various access schemes. 
Finally, we have not given attention to concerns about "margin squeeze", the situation where the entrant's margins over the access charge are too low to break even. For a start, this is difficult to analyze under demand uncertainty: If an access scheme is fixed ex ante, the entrant's margins will be low in bad demand states, which is the very reason that the option not to enter has value to the entrant. To our knowledge, the issue of margin squeeze under demand or cost uncertainty has not yet received attention in the literature.

Acknowledgements We would like to thank the Editor, an anonymous referee, and audiences at PEJ 2019 in Evora and EARIE 2019 in Barcelona for their helpful comments.

\section{Conflict of interest}

The authors declare that they have no conflict of interest.

\section{References}

1. Abrardi L. and C. Cambini, 2019, Ultra-fast broadband investment and adoption : a survey. Telecommunications Policy, 43(3), 183-198.

2. Bourreau, M., C. Cambini and S. Hoernig, 2018. Cooperative investment, access, and uncertainty. International Journal of Industrial Organization, 56, 78-106.

3. Bourreau, M., C. Cambini, S. Hoernig and I. Vogelsang, 2019. Coinvestment options (draft, March).

4. Briglauer, W., S. Frübing and I. Vogelsang, 2015. The impact of alternative public policies on the Deployment of new communications infrastructure - a survey. Review of Network Economics, 13(3), 227-270.

5. Briglauer W., C. Cambini and M. Grajek, 2018. Speeding up the internet: Regulation and investment in the European fiber optic infrastructure. International Journal of Industrial Organization, 61, 613-652.

6. Cambini, C. and Y. Jiang, 2009. Broadband investment and regulation. A literature review. Telecommunications Policy, 33, 559-574.

7. Clark, E. and J. Easaw, 2007. Optimal access pricing for natural monopoly networks when costs are sunk and revenues are uncertain. European Journal of Operational Research, 178, 595-602.

8. Dixit, A.K. and R.S. Pindyck, 1994. Investment under uncertainty. Princeton University Press.

9. European Commission, 2010. Communication from the Commission to the European Parliament, the Council, the European Economic and Social Committee and the Committee of the Regions: a digital agenda for Europe, COM/2010/0245.

10. European Commission, 2016. Communication COM(2016) 587 final, Connectivity for a competitive digital single market - towards a European gigabit society, 14 September.

11. Guthrie, G., J. Small and J. Wright, 2006. Pricing access: Forward-looking versus backward-looking cost rules, European Economic Review, 50, 1767-1789.

12. Hausman, J., 1997. Valuing the effect of regulation on new services in telecommunications, Brookings Papers on Economic Activity. Microeconomics 28, 1-38.

13. Hausman, J., 1999. The effect of sunk costs in telecommunications regulation, in J. Alleman and E. Noam, The new investment theory of real options and its implication for telecommunications economics, Springer.

14. Hori K. and K. Mizuno, 2006. Access pricing and investment with stochastically growing demand. International Journal of Industrial Organization, 24(4), 795-808.

15. Hori K. and K. Mizuno, 2009, Competition schemes and investment in network infrastructure under uncertainty. Journal of Regulatory Economics, 35(2), 179-200. 
16. Inderst R. and M. Peitz, 2014, Investment under uncertainty and regulation of new access networks. Information Economics and Policy, 26, 28-41.

17. Klumpp, T. and X. Su, 2010. Open access and dynamic efficiency. American Economic Journal: Microeconomics, 2, 64-96.

18. Klumpp, T. and X. Su, 2015. Strategic investment under open access: theory and evidence. Journal of Industrial Economics, 63(3), 495-521.

19. Nitsche, R., and L. Wiethaus, 2011. Access regulation and investment in next generation networks. A ranking of regulatory regimes. International Journal of Industrial Organization, 29, 263-272.

20. Pindyck, R.S., 2007. Mandatory unbundling and irreversible investment in telecom networks. Review of Network Economics, 6 (3), 274-298.

21. Vogelsang, I., 2003. Price regulation of access to telecommunications networks. Journal of Economic Literature, 41(3), 830-862. 